ORIGINAL ARTICLE

\title{
Effect of Dexamethasone for Prevention of Neonatal Respiratory Distress Syndrome in mothers undergoing Elective Caesarean Section
}

IFRA MUSHTAQ ${ }^{1}$, RIZWANA NAWAZ², SYEDA SHAISTA WAHEED ${ }^{3}$, MARINA KHALID ${ }^{4}$

${ }^{1}$ Trainee Resident, ${ }^{2}$ Senior Registrar, ${ }^{3}$ Prof. \& Head of Department, ${ }^{4}$ Medical Officer

Nawaz Sharif Medical College/Aziz Bhatti Shaheed Teaching Hospital, Gujrat.

Correspondence to Dr. Rizwana Nawaz, Email: rizwanakhalid92@gmail.com, Mob: 0336-1409010,

\begin{abstract}
Background: Neonatal respiratory distress syndrome (RDS) remains one of the major causes of neonatal mortality and morbidity despite advance in perninatal care. In RDS, ventilation may be affected by homogeneity of the airways with atelectasis and over distension, as hyaline membranes block small airways.

Aim: To compare the frequency of neonatal respiratory distress syndrome with dexamethasone versus control (without dexamethasone) in mothers admitted for elective cesarean section.

Design of the Study: Randomized controlled trial

Place and Duration of Study: Obstetrics and Gynecology Department, Unit- II, Aziz Bhatti Shaheed Hospital, Gujrat from 01-05-2019 to 31-10-2019.

Methodology: A total of 140 patients were included in the study. In group A, females were given 4 doses of $6 \mathrm{mg}$ intramuscular dexamethasone, 12 hours apart pre-operatively. In group B, females were not given any corticosteroids.

Results: Patients ranged between $18-40$ years of age with mean age $31.1 \pm 4.7$ and $31.3 \pm 4.2$ years in Group A \& B, respectively. The mean gestational age in Group-A was $38.0 \pm 0.6$ and in Group-B $38.1 \pm 0.7$ weeks. In Group-A mean BMI was observed $29.1 \pm 3.9$ and Group-B $29.0 \pm 4.3 \mathrm{Kg} / \mathrm{m}^{2}$. In both groups there was a majority of primigravidae. Neonatal RDS in Group-A was found in $6(8.6 \%)$ while in Group-B RDS was found in 18 $(25.7 \%)$. There was a statisticallysignificant difference $(p=0.007)$ between two groups. Stratification with respect to age, gestational age, parity and BMI was also noted.

Conclusion: In conclusion, preoperatively Dexamethasone administration was associated with a significant lowering $(p=0.007)$ of the incidence of neonatal respiratory distress syndrome in mothers of undergoing elective cesarean section.
\end{abstract}

Keywords: Cesarean section; Neonatal respiratory distress syndrome, Dexamethasone

\section{INTRODUCTION}

The acute respiratory distress syndrome (RDS) is an inflammatory disease process of the lungs caused by both direct and indirect insults, and it is clinically characterized by hypoxemia, decreased lung compliance, \& bilateral radiographic infiltrates. ${ }^{1}$ Despite sophisticated and advanced ventilator techniques, bronchopulmonary dysplasia remains a major sequel of perinatal RDS, primarily due to improved survival of extremely premature babies, as well as other factors such as ventilator-induced lung injury, oxygen exposure \& swelling. ${ }^{2}$

Improving the course and outcome of patients with acute RDS is difficult task. Understanding a patient's immune status allows physicians to consider manipulating pro-inflammatory systems more rationally. ${ }^{3,4}$ Corticosteroid treatment has been studied in three different scenarios: prevention in high-risk patients, early high-dose treatment, short-term therapy and prolonged treatment in unresolved cases. ${ }^{5,6}$

Corticosteroids appear to be an ideal therapy for acute lung injury in ARDS, given their protent antiinflammatory \& anti-fibrotic properties. They switch off genes code for pro-inflammatory cytokines and switch on genes that code for anti-inflammatory cytokines. Low doses

Received on 13-04-4021

Accepted on 24-08-2021 of corticosteroids have been shown to prevent and extended cytokine response and may help accelerate the resolution of systemic and pulmonary swelling in pneumonia. ${ }^{7}$ Early postnatal dexamethasone use reduces disease severity \&requirement of oxygen in RDS and that would be beneficial. ${ }^{8}$ Salem et al., reported that the frequency of RDS was $0.8 \%$ with dexamethasone while $4.7 \%$ incontrol group in neonates $(p=00.1) .{ }^{9}$ Ahmed et al., reported that neonates in the treatment group had lower overall incidence of RDS i.e. $7.9 \%$ versus $23.2 \%$ when compared to the control group $(\mathrm{P}<0.05) .{ }^{10}$ While Nada et al., showed that neonatesin the treatment group had almost equal incidence of RDS i.e. $0.65 \%$ versus $1.64 \%$ when compared to the control group $(P>0.05) .{ }^{11}$ The rationale of this study in to compare the frequency of RDS with dexamethasone versus control in women admitted for elective cesarean section during 37-39 weeks. Through literature, it has been observed that RDS can be suppressed with dexamethasone and neonates can be prevented from complications of RDS and mortality. But controversial results have been noticed in literature mentioned above. So, we want to conduct this study to confirm the role of dexamethasone in preventing RDS. This will help to improve our practice and in future we will be able to implement the results of this study for local population. 


\section{MATERIALS AND METHODS}

This randomized controlled trial study was conducted from 01-05-2019 to 31-10-2019 in the Obstetrics and Gynaecology Department in Aziz Bhatti Shaheed Hospital, Gujrat. It was done with the permission of the hospital's institutional review board. Patients gave their informed written consent. Sample size of 140 cases; 70 cases in each group was calculated with $80 \%$ power of study, $5 \%$ level of significant and taking expected percentage of RDS i.e. $7.9 \%$ with dexamethasone and $23.2 \%$ in control groups mothers admitted for elective cesarean section without dexamethasone presenting in at term (37-39 weeks).All females presented with 18-40 years of parity $<5$ presenting at gestational age $>37$ weeks on (LMO) under cesarean section under spinal anesthesia were included from the study. Females with chronic or gestational hypertension (BP $140 / 90 \mathrm{mmHg}$ with convulsions), gestational diabetes, anemia cases were excluded from the study.

The females were then divided into two groups randomly. In group A, females were given 4 doses of $6 \mathrm{mg}$ intramuscular dexamethasone, 12 hour apart preoperatively. In group B, females were not given any corticosteroids. Then all females were followed-up in labour room. After cesarean section females with their neonates were shifted in postnatal wards and followed-up there for 48 hours, ifneonate developed respiratory problems like tachypnea, subcostal \& intercostal retractions, cyanosis and an expiratory grunt on clinical examination. All this information was collected through a pre-designed proforma. All neonates who developed RDS were managed efficiently under pediatric care as per standard protocols. Data were analyzed by SPSS version 20. Quantitative variables like age and BMI were calculated as average and standard deviation. Qualitative variables like RDS were calculated as frequency and percentage. The Chi-square test was used to compare RDS in both groups. Data were stratified according to age, parity, BMI \& gestational age. Chi-square test was applied to compare RDS in stratified groups taking $P$ value $\leq 0.05$ as significant.

\section{RESULTS}

In this study, total 140 patients were included. In group A, females were given 4 doses of $6 \mathrm{mg}$ intramuscular dexamethasone, 12 hour apart preoperatively. In Group B, females were not given any corticosteroids. In Group A, the mean of age, gestational age and BMI was $31.1 \pm 4.7$ year, $38.0 \pm 0.6$ weeks and $29.1 \pm 3.9$ respectively. In Group B, the mean of age, gestational age \& BMl was $31.3 \pm 4.2$, $29.0+4.3 \& 29.0+4.3$ respectively (Table 1$)$. The frequency of age, gestational age and BMI (Table 2). In both groups there was a majority of primigravidae $46(65.7 \%$ ) (Table 3 ). Neonatal RDS Group A was found in 6(8.6\%) while in Group B, RDS was found in 18 (25.7\%), there was a statistically significant difference between two groups $(p=0.007)$. The timing of respiratory distress syndrome in both groups (Table 4).

Stratification with regard to age was observed. In Group A, 2 females had respiratory distress syndrome in 18-30 years of age and 4 were 31-40 years of age. In Group B, 11 females had respiratory distress syndrome in $18-30$ years of age and 7 had in 31-40 years of age. There was statistically significant difference between the groups in 18-30 years of age. Stratification with respect to gestational age and BMI in both groups (Table 5).

Table 1: Mean age, gestational age and BMI $(n=140)$

Table 1: Mean age, gestational age and BMI $(\mathrm{n}=140)$
\begin{tabular}{|l|c|c|}
\hline & Group A (Mean $\pm \mathrm{D})$ & Group B $($ Mean $\pm \mathrm{D})$ \\
\hline Age (years) & $31.1 \pm 4.7$ & $31.3 \pm 4.2$ \\
\hline $\begin{array}{l}\text { Gestational age } \\
\text { (week) }\end{array}$ & $38.0 \pm 0.6$ & $38.1 \pm 0.7$ \\
\hline BMI $\left(\mathrm{Kg} / \mathrm{m}^{2}\right)$ & $29.1 \pm 3.9$ & $2.9 .0 \pm 4.3$ \\
\hline
\end{tabular}

Table 2: Frequency distribution of patients by age, gestational age and BMI

\begin{tabular}{|c|c|c|c|}
\hline & & Group A & Group B \\
\hline \multirow[t]{2}{*}{ Age (years) } & $18-30$ & $28(40 \%)$ & $32(45.7 \%)$ \\
\hline & $31-40$ & $42(60 \%)$ & $38(54.3 \%)$ \\
\hline \multirow{3}{*}{$\begin{array}{l}\text { Gestational age } \\
\text { (week) }\end{array}$} & Mean \pm SD & $38.0 \pm 0.6$ & $38.1 \pm 0.7$ \\
\hline & $37^{+1}$ to 39 & $39(55.7 \%)$ & $32(45.7 \%)$ \\
\hline & $39^{+1}$ to 40 & $31(44.3 \%)$ & $38(54.3 \%)$ \\
\hline \multirow[t]{3}{*}{$\mathrm{BMI}\left(\mathrm{Kg} / \mathrm{m}^{2}\right)$} & Mean \pm SD & $29.1 \pm 3.9$ & $29.0 \pm 4.3$ \\
\hline & $<25$ & $13(18.6 \%)$ & $15(21.4 \%)$ \\
\hline & $\geq 25$ & $57(81.4 \%)$ & $55(78.6 \%)$ \\
\hline \multirow[t]{2}{*}{ Parity } & Primigravida & $46(65.7 \%)$ & $37(52.8 \%)$ \\
\hline & Multigravida & $24(34.3 \%)$ & $33(47.2 \%)$ \\
\hline \multirow{2}{*}{$\begin{array}{l}\text { Respiratory } \\
\text { distress } \\
\text { syndrome }\end{array}$} & Yes & $06(8.6 \%)$ & $18(25.7 \%)$ \\
\hline & No & $64(91.4 \%)$ & $52(74.3 \%)$ \\
\hline
\end{tabular}

Table 3: Comparison of respiratory distress syndrome

\begin{tabular}{|l|l|c|c|}
\hline & & Group A & Group B \\
\hline $\begin{array}{l}\text { Respiratory } \\
\text { distress } \\
\text { syndrome }\end{array}$ & Yes & $6(8.6 \%)$ & $18(25.7 \%)$ \\
\cline { 2 - 4 } & No & $64(91.4 \%)$ & $52(74.3 \%)$ \\
\hline Chi square test & \multicolumn{2}{|c|}{0.007} \\
\hline $\begin{array}{l}\text { Respiratory } \\
\text { distress } \\
\text { syndrome timing }\end{array}$ & $<24 \mathrm{hrs}$ & $6(8.6 \%)$ & $16(22.8 \%)$ \\
\cline { 2 - 4 } & $24-48 \mathrm{hrs}$ & - & $2(2.9 \%)$ \\
\cline { 2 - 4 } & No RDS & $64(91.4 \%)$ & $52(74.3 \%)$ \\
\hline
\end{tabular}

Table 4: Demographic data of patients

\begin{tabular}{|l|c|c|c|}
\hline \multirow{2}{*}{ Age (years) } & & Group A & Group B \\
\cline { 2 - 4 } & Mean \pm SD & $31.1 \pm 4.7$ & $31.3 \pm 4.2$ \\
\cline { 2 - 4 } & $18-30$ & $28(40 \%)$ & $32(45.7 \%)$ \\
\hline \multirow{3}{*}{$\begin{array}{l}\text { Gestational } \\
\text { age(week) }\end{array}$} & $31-40$ & $42(60 \%)$ & $38(54.3 \%)$ \\
\cline { 2 - 4 } & Mean \pm SD & $38.0 \pm 0.6$ & $38.1 \pm 0.7$ \\
\cline { 2 - 4 } & $37^{+1}$ to 39 & $39(55.7 \%)$ & $32(45.7 \%)$ \\
\hline BMI (Kg/m $\left.{ }^{2}\right)$ & Mean \pm SD & $31(44.3 \%)$ & $38(54.3 \%)$ \\
\cline { 2 - 4 } & $<25$ & $29.1 \pm 3.9$ & $29.0 \pm 4.3$ \\
\cline { 2 - 4 } & $\geq 25$ & $57(81.4 \%)$ & $55(78.6 \%)$ \\
\hline \multirow{2}{*}{ Parity } & Primigravida & $46(65.7 \%)$ & $37(52.8 \%)$ \\
\cline { 2 - 4 } & Multigravida & $24(34.3 \%)$ & $33(47.2 \%)$ \\
\hline $\begin{array}{l}\text { Respiratory } \\
\text { distress } \\
\text { syndrome }\end{array}$ & Yes & $06(8.6 \%)$ & $18(25.7 \%)$ \\
\cline { 2 - 4 } & No & $64(91.4 \%)$ & $52(74.3 \%)$ \\
\hline
\end{tabular}

Table 5:Stratification of age, gestational age, parity \& BMI

\begin{tabular}{|c|c|c|c|c|c|}
\hline & \multirow[t]{2}{*}{$\begin{array}{l}\text { Age } \\
\text { (Year) }\end{array}$} & \multirow[t]{2}{*}{ Group } & \multicolumn{2}{|c|}{$\begin{array}{c}\text { Respiratory Distress } \\
\text { Syndrome }\end{array}$} & \multirow[t]{2}{*}{$\begin{array}{c}\mathrm{P} \\
\text { Value }\end{array}$} \\
\hline & & & Yes & No & \\
\hline \multirow{4}{*}{$\begin{array}{l}\text { Age } \\
\text { (years } \\
\text { ) }\end{array}$} & \multirow{2}{*}{$18-30$} & Group-A & 2 & 26 & \multirow{2}{*}{0.011} \\
\hline & & Group-B & 11 & 21 & \\
\hline & \multirow{2}{*}{$31-40$} & Group-A & 4 & 38 & \multirow{2}{*}{0.249} \\
\hline & & Group-B & 7 & 31 & \\
\hline \multirow{4}{*}{$\begin{array}{l}\text { Gestat } \\
\text { ional } \\
\text { age }\end{array}$} & \multirow{2}{*}{$37^{+1}$ to 38} & Group-A & 2 & 37 & \multirow{2}{*}{0.003} \\
\hline & & Group-B & 10 & 22 & \\
\hline & \multirow{2}{*}{$38^{+1}$ to 40} & Group-A & 4 & 27 & \multirow{2}{*}{0.374} \\
\hline & & Group-B & 8 & 30 & \\
\hline \multirow{4}{*}{ Parity } & \multirow{2}{*}{ Primigravida } & Group-A & 3 & 43 & \multirow{2}{*}{0.004} \\
\hline & & Group-B & 8 & 29 & \\
\hline & \multirow{2}{*}{ Multigravida } & Group-A & 3 & 21 & \multirow{2}{*}{0.114} \\
\hline & & Group-B & 10 & 23 & \\
\hline \multirow{4}{*}{$\mathrm{BMI}$} & \multirow{2}{*}{$<25$} & Group-A & 0 & 13 & \multirow{2}{*}{0.088} \\
\hline & & Group-B & 3 & 12 & \\
\hline & \multirow[b]{2}{*}{$\geq 25$} & Group-A & 6 & 51 & \multirow{2}{*}{0.023} \\
\hline & & Group-B & 15 & 40 & \\
\hline
\end{tabular}




\section{DISCUSSION}

In developing countries, the rate of cesarean delivery (CD) is rising beyond the recommended level of World health organization. ${ }^{12}$ Improved surgical techniques and facilities for controlling anticipated postoperative pain and complications such as haemorrhage, infection, and thromboembolism may explain the rise in $C D$ rates. These enhancements increased the procedure's safety and acceptability among both obstetricians and pregnant women. ${ }^{13}$

Although maternal risks have been improved, CD still had effects on the newborns like respiratory composite morbidity including transient tachypnea of new-born (TTN), respiratory distress syndrome (RDS) and even respiratory failure. These complications increase neonatal admissions to incubations and neonatal intensive care units (NICU). Many studies had strengthened on the correlation between scheduled, caesarean delivery at term and respiratory morbidity where $50 \%$ of newborns with respiratory distress were delivered by CD. ${ }^{14}$

Respiratory complications are inversely correlated with gestational age at the time of delivery. As the gestational age increases, the respiratory complications decrease and vice versa. These complications could be reduced by giving antenatal steroids for inducing lung maturity especially when preterm delivery is anticipated. ${ }^{15,16}$ Tita et al, conducted a large study including 24077 scheduled $C D$ at term and found that scheduled CD before 39 weeks was linked to respiratory complications, neonatal hypoglycemia, and admission to the $\mathrm{NICU}^{17}$

In the present study, we found significant difference in the terms of RDS in study and control groups ( $8.6 \%$ vs $25.7 \%$; $p$ value $=0.007$ ), Our data are compatible with those of Ahmed et al ${ }^{10} \mathrm{~T}$ wo other studies also proved that steroids given at term prior surgical delivery were effective in reducing respiratory morbidity, neonatal sepsis and special care units admissions. . $^{9,11}$

On the other side Berry et al, who conducted randomized clinical trial on 130 patients with dexamethasone injection prior to scheduled $C D$ in late preterm gestations (34-37 weeks). They reported no benefits from steroids administration prior to scheduled CD. ${ }^{18}$ Similarly, Kirshenbaum et al, conducted a case controlled study in late preterm babies (34-37 weeks) with no significant difference in the rate of neither respiratory morbidity nor its types between study and control groups. ${ }^{19}$ Srinivasjois et al, conducted a systematic review and meta-analysis including three randomized controlled trials ( $\mathrm{n}=2740$ patients). They concluded that although steroid administration before scheduled CD reduces the neonatal morbidities; however, routine administration of steroids prior scheduled CD should be cautiously because of long-term risks related to steroids. ${ }^{20}$

\section{CONCLUSION}

The conclusion of the study that preoperatively Dexamethasone administration was associated with a significant lowering $(p=0.007)$ of incidence of neonatal respiratory distress syndrome in mothers of undergoing elective cesarean section.

\section{REFERENCES}

1. Spadaro S, Park M, Turrini C, Tunstall T, Thwaites R, Mauri T, et al. Biomarkers for acute respiratory distress syndrome and prospects for personalized medicine. J Inflammation. 2019;16(1):1-11

2. Tu YF, Wang LW, Wang ST, Yeh TF, Huang CC. Postnatal steroids and febrile seizure susceptibility in preterm children. Pediatrics. 2016;137(4).

3. Mokra D, Calkovska A. Experimental models of acute lung injury in the newborns. Physiological Research. 2017;66.

4. Mikolka P, Kopinocova J, KOSATOVA P, Cierny D, Calkovska A, Mokra D. Lung inflammatory and oxidative alterations after exogenous surfactant therapy fortified with budesonide in rabbit model of meconium aspiration syndrome. Physiological Research. 2016;65.

5. Aharon MA, Prittie JE, Buriko K. A review of associated controversies surrounding glucocorticoid use in veterinary emergency and critical care. J Veterinary Emergency and Critical Care. 2017;27(3): 267-77.

6. Khan M, Frankel $H$. Adjuncts to ventilator support part 1: nitric oxide, surfactants, prostacyclin, steroids, sedations, and neuromuscular blockade. Current Problems Surgery. 2013;50(10):424-33.

7. Villar J, Belda J, Anon JM, Blanco J, Perez-Mendez L, Ferrando C, et al. Evaluating the efficacy of dexamethasone in the treatment of patients with persistent acute respiratory distress syndrome: study protocol for a randomized controlled trial. Trials. 2016;17(1):1-10.

8. Argent AC, Kumar P. Rational use of adjunctive therapies: efficacy and efficiency. Pediatric and neonatal mechanical ventilation: Springer; 2015;887-914.

9. Salem MN, Abbas AM, Ashry M. Dexamethasone for the prevention of neonatal respiratory morbidity before elective cesarean section at term. Proceedings in Obstetrics and Gynecology.2016;6(3):1-10.

10. Ahmed MR, Sayed Ahmed WA, Mohammed TY. Antenatal steroids at 37 weeks, does it reduce neonatal respiratory morbidity? A randomized trial. J Mternal-Fetal \& Neonatal Medicine. 2015;28(12):1486-90.

11. Nada A, Shafeek M, EI Maraghy M, Nageeb A, EI Din AS, Awad M. Antenatal corticosteroid administration before elective caesarean section at term to prevent neonatal respiratory morbidity: a randomized controlled trial. European J Obstet \& Gynecol and Reproductive Biology. 2016;199:88-91.

12. Betran AP, Ye J, Moller A-B, Zhang J, Gulmezoglu AM, Torlni MR. The increasing trend in caesarean section rates: global, regional and national estimates: 1990-2014. PloS one. 2016;11(2):e0148343.

13. Dawood AS, Dawood A-Gs, El-Shwaikh SL. A three year retrospective study of caesarean section rate at Tanta University Hospitals. J Gynecol and Obstet. 2017;5(2):25-30.

14. Vidic Z, Blickstein I, Stucin Gantar I, Verdenik I, Tul N. Timing of elective Cesarean section and neonatal morbidity: a populations-based study. J Maternal-Fetal \& Neonatal Medicine. 2016;29(15):2460-2.

15. Sananes N, Koch A, Escande B, Aissi G, Frits G, Roth E, et al. Pilot randomized controlled trial comparing the risk of neonatal respiratory distress in elective caesarean section at 38 weeks gestation following a course of corticosteroids versus caesarean at 39 weeks. European J Obstet \& Gynecol and Reproductive Biology.2017;212:54-9.

16. Freeman $\mathrm{Cl}$, Hezelgrave NL, Shennan AH Antenatal steroids for fetal lung maturity: Time to target more frequent doses to fewer women? Obstetric Medicine. 2015;8(4):172-6.

17. Tita AT, Laie Y, Landon MB, Spong CY, Leveno KJ Varner MW, et al. Timing of elective repeat cesarean delivery at term and maternal perioperative outcomes. Obstet and Gynecol. 2011;117(2 pt 1):280.

18. El-Berry S, Farag M, Sharaf El-dine A, Abdelaty R, Abu El Fotouh F, Prophylactic antenatal corticosteroid administration before elective cesarean delivery at or near term to improve perinatal outcome. Benha J Applied Sciences. 2020;5(2 part (1):1-7.

19. Kirshenbaum M, Mazaki-Tovi S, Amikam U, Mazkereth R, Sivan E, Schiff $E$ et al. Does antenatal steroids treatment prior to elective cesarean section at 34-37 weeks of gestation reduce neonatal morbidity? Evidence from a case control study. Arch Gynecol and Obstet. 2018;297(1):101-7.

20. Srinivasjois R, Silva D. Antenatal steroid administration in medically uncomplicated pregnancy beyond 37 weeks of gestation for the prevention of neonatal morbidities prior to elective caesarean section: a systematic review and meta-analysis of randomized controlled trials. J Maternal-Fetal \& Neonatal Medicine. 2017;30(10):1151-7. 